\title{
VISÃO DAS GESTANTES SOBRE PARTO EM UMA UNIDADE BÁSICA DE SAÚDE DURANTE O PRÉ-NATAL
}

\author{
Erika Zambrano Tanaka ${ }^{1}$, Joana Zambrano Chambrone ${ }^{2}$ \\ ${ }^{1}$ Faculdade Anhanguera de Bauru. Fisioterapia, Bauru, SP. ${ }^{2}$ Universidade Estadual Paulista - UNESP, Curso de \\ Fisioterapia, Presidente Prudente, SP. e-Mail: jo_chambrone@hotmail.com
}

\section{RESUMO}

O parto precisa ser resgatado como momento do nascimento, devolvendo à mulher o direito de ser mãe com humanidade e segurança. O objetivo foi identificar durante o pré-natal qual tipo de parto as gestantes gostariam de ter e identificar o perfil sociodemográficos delas. 0 estudo foi realizado em uma unidade básica de saúde após aprovação do comitê de ética no. 2520/2012. Participaram 25 gestantes com média de idade de 24 anos que responderam um questionário onde $13(52 \%)$ voluntárias relataram preferência por parto normal e $12(48 \%)$ parto cesárea; 18 (72\%) relataram não ter participado de curso de gestante e 7 (28\%) participaram. A partir deste estudo, pode-se conhecer qual a visão das gestantes sobre parto durante o pré-natal e concluir que a unidade básica de saúde e os profissionais precisam promover um atendimento mais humanizado e cursos para gestantes, possibilitando esclarecer as dúvidas do ciclo gestacional.

Palavras-chave: gestação; pré-natal; curso gestante; parto normal; cesárea.

\section{PREGNANT VISION ABOUT CHILDBIRTH IN A BASIC HEALTH UNIT DURING THE PRENATAL}

\begin{abstract}
The delivery needs to be rescued as the time of birth, returning to the woman's right to be a mother to humanity and security. The goal was to identify during the prenatal what type of delivery pregnant women would like to have and identify the sociodemographic profile of them. The study was conducted in a primary health care unit after approval by the ethics committee no. $2520 / 2012$. Participated in 25 pregnant women with a mean age of 24 years who completed a questionnaire in which 13 (52\%) volunteers reported preference for vaginal delivery and 12 (48\%) cesarean delivery; 18 (72\%) reported not having participated in the course of pregnant women and $7(28 \%)$ participated. From this study, one can know what the vision of the women about childbirth during prenatal and conclude that the basic health unit and professionals need to promote a more humanized care and courses for pregnant women allowing the enlightenment of gestational cycle.
\end{abstract}

Keywords: pregnancy; prenatal care; natural childbirth; cesarean section 


\section{INTRODUÇÃO}

O pré-natal é o momento mais apropriado para a preparação ao parto e detecção de possíveis alterações da gestação, tendo que ser iniciada desde seu inicio. Necessitando como estratégias a serem priorizada para obter com eficácia a assistência a gestante e redução da morbimortalidade materna e infantil, o aumento da melhoria da qualidade do atendimento nos serviços de saúde e orientação adequada ${ }^{1}$.

Uma dessas melhorias seria o parto humanizado, a mulher durante a assistência humanizada sente se mais protegida, com confiança e segura durante o parto e ao cuidar do seu bebê. Ficando comprovado durante estudos que o modelo assistencial humanizado modifica o conceito social de parturição, a mulher participa intimamente das decisões de seu próprio corpo, e a equipe atua como facilitadora das decisões ${ }^{2}$.

Neste caso a melhor forma de saber a visão da gestante sobre o parto, é através do pré-natal, e tentando fazer que o pré-natal seja mais esclarecedor, ao invés de deixar a gestante com medo do parto, mas só isso não é necessário, hospitais tem que ter profissionais mais orientados, com melhor conhecimento sobre o parto para que as gestantes realizem mais partos naturais e sem recursos desumanos.
Os objetivos deste trabalho são identificar o tipo de parto ideal para as gestantes, identificar $\quad 0 \quad$ perfil sociodemográficos da amostra e identificar durante o pré-natal qual tipo de parto as gestantes gostariam de ter.

\section{METODOLOGIA}

Trata-se de um estudo quantitativo de caráter descritivo. $\mathrm{O}$ estudo foi realizado em uma unidade básica no interior do Estado de São Paulo, Bauru, onde esta unidade presta atendimento ginecológico, obstétrico, pediátrico, clínica geral e outras atividades como curativos, realização de vacinação, exames, pré e pós consulta de enfermagem.

Foram inclusas na pesquisa 25 gestantes com idade mínima de 18 anos, inscritas no Programa de Pré-Natal do Serviço de Saúde, no período de 02 de Abril a 01 de junho de 2013, que aceitaram participar da pesquisa, assinando o termo de consentimento livre e esclarecido.

0 projeto de pesquisa foi apresentado à Secretaria Municipal de Saúde e coordenação do serviço de saúde da unidade básica por meio de um ofício e após a autorização da realização da coleta dos dados foi encaminhado para o Comitê de Ética em Pesquisa da Faculdade Anhanguera, sendo registrada sob no. 2520/2012, obtendo aprovação do mesmo. 


\section{RESULTADOS}

Foram entrevistadas 33 gestantes, as segundas-feiras à tarde e durante duas semanas as sextas feiras de manhã. Foram excluídas 08 gestantes por serem menores de 18 anos, não houve recusa na participação.

Participaram 25 gestantes, com idade variando de 18 a 39 anos, média de 24 anos. Destas 05 (20\%) são solteiras, 08 (32\%) são amasiadas e 12 (48\%) são casadas, as casadas tiveram um percentual maior. (Tabela1)
Em relação ao tipo de parto que pretende realizar nesta gravidez, 13 gestantes $(52 \%)$ relataram preferencia por parto normal e 12 (48\%) parto cesárea.

Em relação se já participaram de algum curso de gestantes houve predominância com 18 gestantes (72\%) que relataram não ter participado de nenhum curso de gestantes e $07 \quad(28 \%)$ sim participaram do curso.

Tabela 1. Distribuição das gestantes em relação a idade, estado civil, raça e escolaridade.

\begin{tabular}{lr|c}
\hline VARIÁVEL & NÜMERO & (\%) \\
\hline G estantes & 25 & $\mathbf{1 0 0}$ \\
\hline Idade & 12 & $48 \%$ \\
$18 ? 25$ anos & 7 & $28 \%$ \\
$25 ? 30$ anos & 4 & $16 \%$ \\
$30 ? 35$ anos & 2 & $8 \%$ \\
$35 ? 39$ anos & 2 & \\
\hline Estado Civil & 12 & 48 \\
Casada & 05 & 20 \\
Solteira & 08 & 32 \\
Amasiada & &
\end{tabular}

$\begin{array}{lll}\quad \text { Raça } & & \\ \text { Branca } & 09 & 36 \\ \text { Parda } & 10 & 40 \\ \text { Negra } & 06 & 24 \\ \text { Escolaridade } & & \\ \text { Colegial } & & \\ \text { Completo } & 11 & 44 \% \\ \text { Colegial } & & \\ \text { incompleto } & 11 & 44 \% \\ \text { Analfabeta } & 1 & 4 \% \\ \text { Ensino técnico } & 1 & 4 \% \\ \text { Ensino Superior } & 1 & 4 \%\end{array}$


Com relação a Idade Gestacional 07 gestantes (28\%) estavam no 1 o trimestre da gestação,09 (36\%) no 20 trimestre e 09 (36\%) no 3 o trimestre da gestação.

Perguntando se já tiveram filhos 18 gestantes (72\%) disseram que sim e 07 (28\%) não, das que tiveram filhos 12 foram de parto normal e 06 cesárea.

Em relação aos meses que iniciaram o pré-natal $04(16 \%)$ iniciaram no primeiro mês de gestação, 05 (20\%) no segundo mês,10 ( $40 \%)$ no terceiro, 03 (12\%) no quarto e 03 (12\%) no 5 mês. (Gráfico 1). Destas 23 (92\%) fizeram o pré-natal regularmente e 02 (8\%) não. As duas gestantes que disseram não realizar 0 pré-natal regularmente ,informaram que o motivo foi "Funcionários agendam errado" $(8$ meses fez 6 consultas),"Não tinha certeza da gravidez" (5 meses e apenas 1 consulta ).

Gráfico 1. Distribuição em relação ao Mês que iniciaram o pré-natal

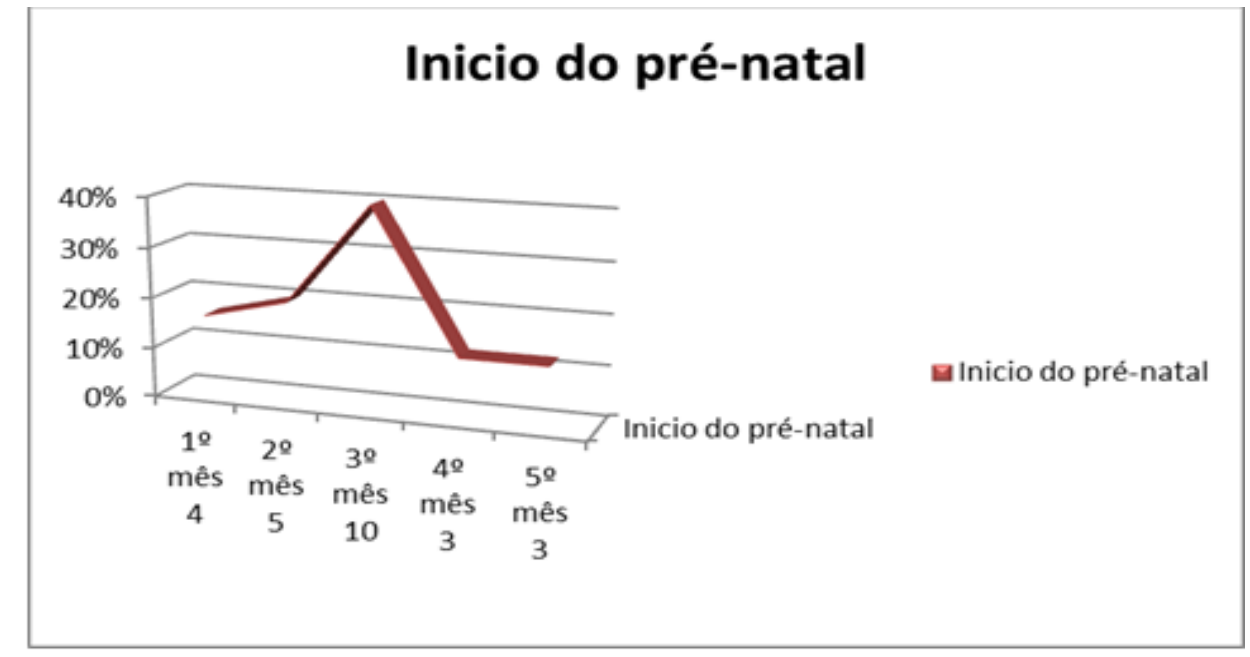

Em relação as consultas realizadas 06 gestantes (24\%) realizaram uma primeira consulta,03 (12\%) duas consultas, 06 gestante (24\%) três consultas, 01(4\%) quatro consultas, $01(4 \%)$ cinco consultas, 3 gestantes (12\%) seis consultas e 05 gestantes (20\%) realizaram mais de 06 consultas de pré-natal.

Em relação as orientações recebidas sobre partos durante o pré-natal 5 (20\%) gestantes relataram ter recebido orientações durante o pré-natal, 15 (60\%) não ter recebido e 5 (20\%) estavam realizando a primeira consulta não tendo passado ainda pelo médico.

Das que disseram sim: uma gestante relatou que o parto cesárea é melhor, mas prefere o parto normal; duas falaram que o parto normal é o ideal e o parto cesárea só deve acontecer em caso de complicações; uma falou que tem horror do parto normal devido ao parto anterior onde o parto 
normal não foi possível por não haver dilatação e então foi encaminhada para o parto cesárea; uma relatou que o parto normal é melhor que o parto cesárea, mas tem medo do parto normal pelo que as pessoas dizem.

Das que disseram não: onze gestantes disseram que gostariam de receber orientação durante o pré-natal, pois tem muitas duvidas e acham importante a orientação; uma disse que gostaria que fossem utilizados outros meios de comunicação para informações sobre o parto, mas acredita que se a mulher quer um tipo de parto isso não vai mudar com a informação recebida; uma disse que gostaria que o assunto fosse abordado por uma mulher do que por um homem; uma disse que o médico faz a consulta muito rápido, não dando oportunidade para esclarecer suas duvidas; uma disse que iria conversar na consulta a ser realizada no dia da entrevista e uma disse não tinha informação, foi mal atendida no parto anterior e tem medo de uma nova experiência.

Em relação ao conhecimento sobre os benefícios do parto normal, 16 gestantes (64\%) conhecem os benefícios do parto normal e 09 gestantes (36\%) não conhecem os benefícios, 12 gestantes das 16 que relataram conhecer $\mathrm{o}$ beneficio do parto normal $(75 \%)$ citaram os benefícios como "recuperação é melhor".
Perguntando se pretendiam participar de algum curso de gestantes das 18 gestantes que não participaram de nenhum curso de gestantes, 14 (78\%) pretende participar e 4 (22\%) não pretendem participar.

\section{DISCUSSÃO}

Das 33 gestantes do nosso estudo, 20 possuíam um relacionamento estável. De acordo com Melchiori, em seu estudo "Preferência de Gestantes pelo Parto Normal ou Cesariano" ele encontrou que $75 \%$ das gestantes eram casadas ou viviam com seus companheiros, $25 \%$ eram solteiras e $5 \%$ haviam se separado de seus parceiros ${ }^{3}$.

Em relação à raça, a branca e a negra foram muito semelhantes. $O$ artigo de Mandarino "Aspectos relacionados à escolha do tipo de parto: um estudo comparativo entre uma maternidade pública e outra privada, em São Luís, Maranhão, Brasil", na população atendida na maternidade pública havia um predomínio de mulheres pardas, demonstrando ser condizente com a pesquisa realizada, brancas $35(21,5 \%)$, pardas $100(61,3 \%)$ e negras $28(17,2 \%)^{4}$.

A maioria das gestantes entrevistadas reconhece a importância do parto normal e vê este como mais vantajoso. O Ministério da Saúde recomenda o parto normal (via vaginal) como a melhor forma de dar a luz, embora a cesariana seja indicada em alguns 
casos. Diante disso podemos citar as vantagens e desvantagens do parto normal e cesárea ${ }^{5}$.

Quando se realiza parto cesárea os hormônios prolactina e ocitocina não são produzidos o suficiente e o leite demora a descer, pois não é produzido quantidade suficiente, eles são fabricados durante o trabalho de parto e são fundamentais para acelerar a produção de leite, sendo outra vantagem do parto normal, o organismo materno se prepara para o nascimento e o bebê pode mamar já na sala de parto ${ }^{5}$.

Segundo Nagahama em seu estudo, ele relata que o parto cesárea custa em média duas a três vezes o valor do parto normal, sendo um desperdício de milhões de reais por ano no sistema único de saúde, cada cesárea que não é necessária, causa risco maiores de complicações como hemorragia, infecções e complicações anestésicas que induzem ao aumento de mortalidade materna, para o $\mathrm{RN}$ devido a prematuridade ${ }^{6}$.

Neste trabalho pode se observar que há uma taxa de infecção relativamente maior relacionada ao parto cesárea em comparação ao parto normal, consequentemente devido á incisão cirúrgica, tempo maior de cirurgia com perda de sangue, levando ao aumento de infecção.

A partir deste estudo, pode-se conhecer qual a visão das gestantes sobre o parto durante o pré-natal. Sabemos que o pré-natal é o momento de informações e esclarecimentos à gestante quanto à: evolução da gestação, fatores de riscos, possíveis complicações, preparação para o parto e cuidados com o RN. Essas informações deveriam fazer parte de uma assistência pré-natal humanizada e de direito da gestante, mas o que foi observado durante a pesquisa é que infelizmente isso não acontece nessa unidade.

As gestantes não recebem informações adequadas sobre o parto pelo obstetra e nem há na unidade cursos ministrados por profissionais da saúde que ofereçam informações e preparo para elas. A maioria das gestantes entrevistadas detém um conhecimento empírico sobre o parto, $72 \%$ das entrevistadas nunca participaram de curso para gestantes e somente uma minoria teve acesso ao curso ministrado por alguma entidade filantrópica.

A OMS e estudos recentes mostram que há um aumento do número de partos cesárea em relação ao normal, mas segundo a pesquisa realizada, $52 \%$ das gestantes demonstraram durante o pré-natal a preferência pelo parto normal devido aos seus benefícios, sendo o de "a recuperação é melhor" citado como o beneficio principal, demonstrando assim uma divergência entre a preferencia pelo tipo de parto durante $o$ pré-natal e o parto realizado. 
Para prover uma mudança nesta realidade, seria necessário que a unidade de saúde e os profissionais responsáveis pelo atendimento às gestantes promovessem um atendimento mais humanizado e cursos para gestantes possibilitando esclarecer todas as dúvidas do ciclo gravídico-puerperal.

Acreditamos que seria interessante a continuação deste estudo para que, por exemplo, saibamos se o parto realizado ao final da gestação foi o mesmo de preferência durante o pré-natal; implantar o curso de gestantes e saber como a detenção de informações científicas influenciaram na escolha do parto.

\section{REFERÊNCIAS}

1. Versiani, C C; Mendonça, J M G; Vieira, M A; Roseni, R. Maternidade segura relato de experiência. Rev. APS. 2008; 11(1):109-114.

2. Silva, LM; Barbieri, M; Fustinoni, SM. Vivenciando a experiência da parturição em um modelo assistencial humanizado. Rev. bras. enferm. [online]. 2011; 64(1):60-65. DOI: $\quad$ http://dx.doi.org/10.1590/S003471672011000100009.

3. Melchiori LE, Maia AC, Bredariolli RN, Hory RI. Preferência de gestantes pelo parto normal ou cesariano. Interação Psicol. 2009;13(1):13-23.

http://dx.doi.org/10.5380/psi.v13i1.9858

4. Mandarino, NR et al. Aspectos relacionados à escolha do tipo de parto: um estudo comparativo entre uma maternidade pública e outra privada, em São Luís, Maranhão, Brasil. Cad. Saúde Pública [online]. 2009; 25(7):1587-1596. DOI:
http://dx.doi.org/10.1590/S0102311X2009000700017.

5. SAÚDE, Ministério. Parto, Aborto e Puerpério, Assistência Humanizada à mulher. Ministério da Saúde, Brasil; Brasília; 2001; 1: $14-27$.

6. Nagahama, EEl; Santiago,SM .Parto humanizado e tipo de parto: avaliação da assistência oferecida pelo Sistema Único de Saúde em uma cidade do sul do Brasil. Rev. Bras. Saude Mater. Infant. [online]. 2011,11(4):415-425. DOI: http://dx.doi.org/10.1590/S1519-

38292011000400008.

Recebido para publicação em 19/08/2014 Revisado em 20/08/2014

Aceito em 25/08/2014 